\title{
Juventude negra e práticas escolares: anotações para uma perspectiva não homogeneizante do jovem negro
}

\author{
Black youth and school practices: \\ Notes from the non-homogenising perspective of the young black man
}

Heloise da Costa SILVA*

https://orcid.org/0000-0002-5073-1050

\section{Carlos Henrique dos Santos MARTINS** \\ https://orcid.org/o0oo-0002-9219-7351}

\begin{abstract}
Resumo: $\mathrm{O}$ artigo traz a identidade negra não homogeneizante como ponto crucial para debates sobre relações étnico-raciais, principalmente nas instituições escolares. Propõe a reflexão a respeito da construção de identidade de alunos e alunas negros e negras em uma perspectiva que observe suas singularidades. Partindo da Lei 10.639/03, problematiza estruturas educacionais que reforçam o racismo, além de reafirmarem a ideia de uma identidade negra positivada, sem atentar para a seguinte discussão: que identidade negra é essa? Partindo de revisão bibliográfica e baseando-nos em Hall (2003), sugerimos pensar na ingênua noção que essencializa o negro, como se existisse um ser negro que reunisse todas as características necessárias para ser classificado como tal. São abordados conceitos acerca de identidade e juventude, visando estabelecer a relação entre eles, quando vinculados aos jovens negros e negras, em ambiente escolar.
\end{abstract}

Palavras-chave: Identidade negra. Juventude negra. Racismo e educação.

Abstract: The article presents non-homogenising black identity as a crucial element in debates regarding ethno-racial relations, especially in school institutions. It proposes that we reflect on the identity construction of black students from a perspective that observes their individuality. Starting from Law 10.639/03, it questions educational structures that reinforce racism while reaffirming the idea of a positive black identity, without paying attention to the following discussion: what black identity is this? From a literature review and based on Hall (2003), we suggest thinking of a naive notion that essentialises the black, as if there were a black being that had all the characteristics necessary to be classified as such. Concepts about identity and youth are approached, aiming to establish the relationship between them when linked to young black people in a school environment.

Keywords: Black identity. Black youth. Racism and education.

Submetido em: 29/10/2019. Revisado em: 7/4/2020. Aceito em: 14/4/2020.

\footnotetext{
* Professora de Língua Portuguesa. Mestra em Relações Étnico-Raciais. Analista de Ações Afirmativas e Treinamento em Empresas no Instituto Identidades do Brasil. (ID_BR, Rio de Janeiro, Brasil). Rua Farani, 23, sala 104 - Botafogo, Rio de Janeiro, CEP.:22231-020. E-mail: helo des@hotmail.com. ** Professor de Educação Física. Doutor em Educação. Professor do Programa de Pós-Graduação em Relações Étnico-Raciais do Centro Federal de Educação Tecnológica Celso Suckow da Fonseca. (CEFET, Rio de Janeiro, Brasil). Avenida Maracanã, 229, bloco E, $5^{\circ}$ andar, Rio de Janeiro (RJ), CEP: 20271-110. E-mail: chsmlobo@gmail.com.
} copiar e redistribuir o material em qualquer suporte ou formato, bem como adaptar, transformar e criar a partir deste material para qualquer fim, mesmo que comercial. O licenciante não pode revogar estes direitos desde que você respeite os termos da licença. 


\section{Introdução}

$\mathrm{Q}$ uando se fala em juventude, de forma geral, o que se observa é a prática recorrente de um discurso homogeneizante, o qual insere todos os indivíduos classificados como tais em um contexto de características muito similares. Muitas vezes, se relaciona os e as jovens a um problema ou, ainda, os e as classificam como seres em preparação para se desenvolverem e amadurecerem no futuro, na idade adulta.

Nesse contexto, fica aberto o debate acerca da juventude como fase da vida pela qual todos/as deveremos passar (PAIS, 2003) e para a qual há uma série de rituais, normas e regras a serem cumpridas. Para além dessa perspectiva linear, o que estamos propondo é o debate que leve em conta a juventude não como fase inexorável, como recorte geracional, pois acreditamos na possibilidade de olhar o e a jovem como sujeito social que produz ações específicas, tendo as culturas juvenis como espaço político de elaboração de suas demandas.

De acordo com Helena Abramo,

[...] parece estar presente, na maior parte da abordagem relativa aos jovens, tanto no plano da sua tematização como das ações a eles dirigidas, uma grande dificuldade de considerar efetivamente os jovens como sujeitos, mesmo quando é essa a intenção, salvo raras exceções; uma dificuldade de ir além da sua consideração como "problema social" e de incorporá-los como capazes de formular questões significativas, de propor ações relevantes, de sustentar uma relação dialógica com outros atores, de contribuir para a solução dos problemas sociais, além de simplesmente sofrê-los ou ignorá-los (ABRAMO, 1997, p. 328).

Assim, o/a jovem está sempre sendo tratado/a como sujeito incompleto, que atravessa um período de desenvolvimento, incapaz de expressar suas vontades, desejos e anseios, bem como produzir, criar, revolucionar. Dessa forma, em grande parte do que se produz a respeito, é, de modo geral, sobre o/a jovem - nunca com ele ou com ela - a quem é negada a voz e a possibilidade de posicionamento e construção de um discurso em primeira pessoa e não apenas a partir do que criam a seu respeito.

Para Bourdieu (1983, p.2), a juventude é apenas uma palavra. Ele entende isso porque não a considera como um conjunto de dados, mas uma construção elaborada socialmente, na "[...] luta entre os jovens e os velhos [...]"; além disso: "[...] somos sempre o jovem ou o velho de alguém”. Nesse sentido, abarca um caráter discursivo, uma vez que se estabelece a partir das relações de sentido constituídas em sociedade.

Nessa perspectiva, essa definição parte de um critério etário para definir a juventude, em que pretende demonstrar que a classificação entre jovem e velho se estabelece de forma arbitrária. Assim, ela se configura como uma categoria relacional, já que necessita da comparação com o outro para se confirmar, ao mesmo tempo em que é ela quem dita o padrão social a ser seguido.

Para Dayrell (2007), classificar a juventude como uma categoria sociológica é uma tarefa difícil, uma vez que o conceito estará sempre atrelado a aspectos ligados à história e à cultura. Assim, o autor a compreende como uma condição associada às questões sociais

Argum., Vitória, v. 12, n. 1, p. 50-66, jan./abr. 2020. | ISSN 2176-9575 
e uma forma de representação. Dessa forma, juventude relaciona-se tanto a características físicas (aparência, forma muscular, por exemplo) e psicológicas (visão de mundo, compreensão do indivíduo de sua situação) quanto a características sociais, como classe, raça e gênero, por exemplo.

Esta última definição nos possibilita pensar na juventude como uma categoria que não se restringe apenas à faixa etária, mas que está intimamente ligada a diversos outros contextos que farão com que a classificação de um sujeito como jovem seja o tempo inteiro redefinida e reelaborada.

A partir disso, podemos pensar, assim como Margullis E Urresti, que "[...] a condição histórico-cultural de juventude não se oferece de igual forma para todos/as os/as integrantes da categoria estatística jovem [...]" (MARGULLIS; URRESTI, 1996, p. 25), o que o isentaria da condição de mero signo para inseri-lo/a em contextos em que outros condicionantes são acionados, como fatores históricos, sociais e materiais, por exemplo. Nesse sentido, olhar a juventude a partir do recorte geracional surge como uma significativa possibilidade de diálogo com essa categoria sociológica, tendo como foco principal as culturas juvenis (PAIS, 2003).

É de posse dessa concepção que este trabalho se organiza e aponta algumas anotações. Apresentamos como centralidade a juventude negra e processos de escolarização. Assim, se consideramos que outras condições além da idade estão presentes na categorização do/a jovem, podemos, então, pensar a raça como um fator condicionante para as diferentes vivências que um/a jovem negro/a terá em relação a um/a jovem não-negro/a.

Outro ponto versa a respeito da dupla estereotipação, formulada a partir da junção jovem + negro/a, a qual poderá se engendrar no processo de formação de uma identidade jovem e negra não- homogeneizante. Somam-se a isso, os modos como a escola assume ou não o debate a respeito do racismo e invisibilização desse sujeito no espaço escolar.

Para isso, observamos também de que forma práticas educativas que se pretendem antirracistas e com respaldo na Lei 10.639/03 (BRASIL, 2003) ${ }^{1}$ contribuem para um novo tipo de elaboração de estereótipo: o que pressupõe a busca de uma identidade negra absoluta, que não leva em consideração valores e anseios individuais de jovens negros e negras.

\section{Juventude negra: aspectos preliminares}

Pensar nas especificidades do/a jovem negro/a é um desafio que nos parece ainda pouco enfrentado pelas ciências sociais. Dessa forma, ao nos debruçarmos preliminarmente em uma análise da juventude negra veremos que esta relação de disputa entre "jovens e velhos", defendida por Bourdieu, poderá se apresentar de forma distinta do que se considera uma juventude padrão - branca e classe média. Partindo da ideia de que a

${ }^{1}$ Lei que altera a Lei. 9.394, de 20 de dezembro de 1996, que estabelece as diretrizes e bases da Educação nacional, para incluir no currículo oficial da Rede de Ensino a obrigatoriedade da temática "História e cultura Afro-Brasileira" e dá outras providências. 
juventude se enquadra em uma discussão que engloba uma certa “[...] complexidade na relação entre idade social e idade biológica [...]" (MARGULLIS; URRESTI, 1996, p .2), apontada pelos autores, podemos pensar que, para o/a jovem negro/a, esta diferenciação é quase inexistente socialmente, pois ele ou ela não são vistos da mesma forma que um/uma jovem branco/a.

Em outras palavras, o que queremos dizer é que os negros e a negras já nascem adultos e adultas, uma vez que se nega a eles e a elas, além da proteção integral estabelecida pelo Estatuto da Criança e do Adolescente (ECA), por exemplo, por meio da atenção a necessidades básicas, como educacionais, econômicas, de saúde, moradia, a possibilidade de serem pensados e pensadas como sujeitos que possuem anseios e diferenças políticas, subjetivas, emocionais etc.

Nesse sentido, dizer que negros e negras já nascem adultos/as significa dizer que a categoria negro/a está acima de qualquer outra diferenciação social que se possa fazer, e esta não diferenciação também está na relação geracional. Assim, nas palavras de Fanon:

Há uma zona de não-ser; uma região extraordinariamente estéril e árida, uma rampa essencialmente despojada, onde um autêntico ressurgimento pode acontecer. A maioria dos negros não desfruta do benefício de realizar esta descida aos verdadeiros infernos (FANON, 2008, p. 26).

Essa zona de não-ser, descrita por Fanon, nos demonstra que o/a negro/a, socialmente, não é nada além de sua cor, o que não dá espaço para desfrutar de uma infância ou, neste caso, específico de discussão, de uma juventude. Este/a negro/a representa e é representado/a por uma construção de estereótipos que o/a enquadram apenas numa condição racial. Ele/a não é uma criança, é um negro/a; ele/a não é um/a jovem, é um negro/a; ele/a não é um/a adulto/a, é um negro/a. Retoma-se aqui o antigo debate acerca do que se considerava o jovem como problema: este é marcado, dentre outros aspectos, pela violência e seria o jovem negro perigoso. Se fizermos um recorte de gênero, notaremos que este jovem-problema se transforma na grávida na adolescência e na menina negra sensual e objetificada, por exemplo.

Um retrato disso está na criminalização, ou não, dos jovens dos dois grupos raciais, quando em situação de infração. Ao observarmos, por exemplo, em caso de crimes do mesmo tipo, jovens negros e brancos são retrados nas manchetes de maneira distinta. Podemos perceber isso a partir das seguintes notícias:

Ele é um sementinha do mal': PM paulista vai até a casa da mãe do garoto pedir para ela encomendar o caixão do filho [...] O diminutivo se explica: Miguel tinha apenas 1 metro e 33 centímetros de altura. Era um menininho negro, inteligente e sonhador (SILVA; CAPRIGLIONE, 2019, não paginado).

Jovem de classe média alta é preso por suspeita de tráfico em boates de $\mathrm{BH}$ [...] A Polícia Civil de Minas Gerais prendeu um jovem de 23 anos, suspeito de comercializar maconha, haxixe e drogas sintéticas em festas e boates de Belo Horizonte (LOVISI, 2019, não paginado).

Argum., Vitória, v. 12, n. 1, p. 50-66, jan./abr. 2020. | ISSN 2176-9575 
Para o primeiro grupo, os adjetivos traficantes, criminosos, bandidos são largamente atribuídos, enquanto para os pertencentes ao segundo grupo as palavras jovem ou adolescente aparecem sempre no sentido de abrandar o ato infracionário cometido (COSTA, 2019).

Além disso, há os discursos acerca da redução de maioridade penal ${ }^{2}$, bem como a imposição de penas mais rígidas nas medidas socioeducativas. Quando se fala em aplicação da lei, de pena de morte, de tratar como adulto aquele que comete crime é a um grupo específico de jovens a quem se visa implantar tais medidas, e este é o grupo dos/as jovens negros/as. Isso se dá porque o discurso criminalizante que coloca pessoas negras como inatamente criminosas tem se perpetuado socialmente e encontra reforço pelos diversos estigmas que se sustentam, inclusive, através dos discursos midiáticos. A construção social da imagem do negro como vagabundo é memória trazida do período escravocrata e que quase sempre é acionada para adjetivar esses jovens.

De acordo com o Conselho Regional de Serviço Social de Minas Gerais:

A maioria das mulheres negras sofrem violência desde a infância, onde aprendem desde cedo que seus corpos não são valiosos e vivem com o conhecimento de que não são desejadas. Muitas meninas negras crescem com a certeza de que cada aspecto do seu corpo é considerado ruim e, assim, acreditam que a única forma de alcançar um patamar de igualdade com as mulheres brancas é 'corrigindo' suas características com a ajuda da tecnologia. A hipersexualização do corpo feminino negro, com ênfase em suas características consideradas 'excêntricas' e 'diferentes do convencional', promove uma falsa valorização das garotas negras, que deixam de ser completamente rejeitadas para se tornarem aceitas, desde que seus corpos sejam submetidos à exotificação racial (CONSELHO REGIONAL DE SERVIÇO SOCIAL, [201-], p. 2).

Este cenário se apresenta para jovens negras das mais diversas formas: seja pelas representações repetitivas da nudez de celebridades negras que só se destacam no carnaval - vide a Globoleza3- ou destaque para a beleza negra que sempre é posta em tom de sensualidade, tornando esta jovem um não-sujeito, um objeto, uma vez que não se destacam suas outras particularidades, capacidades e subjetividades.

Nessa perspectiva, os/as jovens negros/as que devem ser tratados/as como adultos/as já o são tratados/as assim desde sempre, vide as medidas socioeducativas e, antes disso, como crianças negras moradoras de áreas favelizadas, por exemplo, desde cedo experimentam a violência policial, a destituição de direitos, em que muitas são

\footnotetext{
${ }^{2}$ Esses discursos estão potencializados a partir da Proposta de Emenda à Constituição $\mathrm{n}^{\circ}{ }^{115}$, de 2015, que: "Estabelece que são penalmente inimputáveis os menores de dezoito anos, sujeitos às normas da legislação especial, ressalvados os maiores de dezesseis anos, observando-se o cumprimento da pena em estabelecimento separado dos maiores de dezoito anos e dos menores inimputáveis, em casos de crimes hediondos, homicídio doloso e lesão corporal seguida de morte" (BRASIL, 2015, p. 1).

3 É o nome atribuído à mulher que samba nua ou seminua nas vinhetas de carnaval da Rede Globo de Televisão. Embora o formato dessa apresentação tenha mudado em vista de recorrentes críticas dos movimentos negros e feministas, ainda paira no imaginário popular a imagem de uma mulher negra que demarca a abertura do carnaval na televisão, mostrando seu corpo e sensualidade.
} 
revistadas (FOTO..., 2018)4, agredidas e mortas5. Assim, o racismo estrutural em nossa sociedade retira de pessoas negras a possibilidade de responderem por sua individualidade, mas passam a responder por seu grupo racial, e isso se dá desde muito cedo.

Os discursos criminalizantes e homogeneizantes podem ser observados também nas instituições escolares. Não é raro se ouvir de professores e funcionários de escolas, principalmente se situadas em áreas consideradas de risco, como favelas no Rio de Janeiro, em que a maioria dos alunos e alunas matriculados/as é de origem negra, falas como este já vai ser bandido; sementinha do mal. É possível observar uma padronização idealizada do ser jovem. Não à toa é chamado/a de aluno/a, ou seja, sem luz.

De um modo geral, como o/a jovem negro/a, por vezes, não identifica aquele espaço como sendo seu, onde não se reconhece através de práticas docentes e dos currículos que estão direcionados à cultura eurocêntrica, é plausível que haja reações de insatisfação e suas múltiplas formas de expressão. Assim, o espaço escolar tem traduzido as desigualdades e preconceitos que se encontram na sociedade, de modo geral, e o racismo estruturante das relações sociais no Brasil (ALMEIDA, 2018) também faz com que o sistema de ensino abarque tanto o apagamento do/a aluno/a negro/a como sujeito dotado de saberes, subjetividades, complexidades e peculiaridades e relega a ele/ela o status de representante de uma raça socialmente considerada apta para o crime ou para a sexualização. Como se não bastasse, essa estigmatização também pode contribuir sobremaneira para detonar processos de desidentização, o que, em muitos casos, pode resultar na evasão escolar.

Nesse contexto, vale destacar a importância da implantação da lei 10.639/03 como possibilidade de reorganizar o currículo escolar em todos os níveis de ensino, cujas diretrizes apontam para as múltiplas formas de sua implementação. Estas estão expressas no Plano Nacional de Implementação das Diretrizes Curriculares Nacionais Para Educação das Relações Étnicorraciais e Para o Ensino de História e Cultura AfroBrasileira e Africana (2009) ${ }^{6}$.

O referido Plano:

Está dirigido formalmente para que, sistemas e instituições de ensino compram o estabelecido nas leis 10.639/03 e 11.645/087. Assim, as instituições devem

\footnotetext{
4 Sobre este fato ver Foto... (2018).

5 Tal quadro se intensificou, principalmente, no Rio de Janeiro a partir do início do mandato de governador eleito Wilson Witzel, o qual declara abertamente ser adepto de uma política em que a polícia está autorizada a "atirar primeiro", "mirar na cabecinha". Isso também pode ser notado pela adoção de helicópteros que participam de incursões policiais, os quais atiram indiscriminadamente em áreas de conflito - operações das quais ele gosta de participar pessoalmente - ou, ainda, na comemoração eufórica pela morte de um jovem negro, assassinado pela polícia mesmo após de rendido em sequestro ocorrido na Ponte Rio-Niterói, em agosto de 2019.

${ }^{6}$ No sentido de facilitar a leitura e redação deste texto, o referido Plano passa a ser identificado pela sigla PNI.

7 Altera a Lei no 9.394, de 20 de dezembro de 1996, modificada pela Lei no 10.639, de 9 de janeiro de 2003, que estabelece as diretrizes e bases da educação nacional, para incluir no currículo oficial da rede de ensino a obrigatoriedade da temática "História e Cultura Afro-Brasileira e Indígena" (BRASIL, 2003).
}

Argum., Vitória, v. 12, n. 1, p. 50-66, jan./abr. 2020. | ISSN 2176-9575 
realizar revisão curricular para a implantação da temática, quer nas gestões dos Projetos Políticos Pedagógicos, quer nas Coordenações pedagógicas e colegiados, uma vez que possuem a liberdade para ajustar seus conteúdos e contribuir no necessário processo de democratização da escola, da ampliação do direito de todos e todas à educação, e do reconhecimento de outra matrizes de saberes da sociedade brasileira (BRASIL, 2009, p. 29).

Apesar de não ser objeto desse texto a análise do referido Plano, importa destacar suas efetivas contribuições para o processo de democratização da educação, bem como para o fortalecimento das identidades juvenis negras tendo a escola como espaço privilegiado no qual ações pedagógicas sejam desenvolvidas tendo como norte a referida lei, explicitada pelo PNI. Nesse sentido, podemos destacar o Art, 2º, § 2 e § 3, da Resolução nำ1/o4 do Conselho Nacional de Educação:

\begin{abstract}
$\S 1^{\circ}$ A Educação das Relações Étnico-Raciais tem por objetivo a divulgação e produção de conhecimentos, bem como de atitudes, posturas e valores que eduquem cidadãos quanto à pluralidade étnico-racial, tornando-os capazes de interagir e de negociar objetivos comuns que garantam, a todos, respeito aos direitos legais e valorização de identidade, na busca da consolidação da democracia brasileira.

$\S 2^{\circ}$ O Ensino de História e Cultura Afro-Brasileira e Africana tem por objetivo o reconhecimento e valorização da identidade, história e cultura dos afrobrasileiros, bem como a garantia de reconhecimento e igualdade de valorização das raízes africanas da nação brasileira, ao lado das indígenas, europeias, asiáticas (BRASIL, 2009, p. 57).
\end{abstract}

Observa-se que, em ambos os parágrafos, a valorização da identidade está posta como um dos objetivos a serem alcançados no processo de reestruturação e de reorganização da educação escolar numa perspectiva democrática. $O$ desafio é repensar a escola cujos espaços incorporem múltiplas formas de tratar as diferentes expressões culturais juvenis que, por vezes, estão silenciadas e invisibilizadas. A construção da identidade negra está posta como um desafio constante para um segmento da sociedade que frequentemente enfrenta mecanismos de desqualificação de suas culturas, sua história, suas origens etc., nesse caso, a juventude negra.

Se considerarmos que a escola é um dos principais espaços de socialização dos jovens negros, ela como espaço de reprodução das desigualdades sociais (FREIRE, 1987) passa necessariamente pela perpetuação do racismo, pois como dissemos anteriormente a maior parcela da juventude presente em seus espaços é pobre e, desta, a maioria é preta. Dessa forma, pressupõe-se que a adoção deste tipo de postura pode contribuir de forma bastante potente para a formação de uma identidade negativa do jovem negro e da jovem negra.

De acordo com Bourdieu (1983), “[...] a escola, sempre se esquece disto, não é simplesmente um lugar onde se aprende coisas, saberes, técnicas, etc.: é também uma instituição que concede títulos, isto é, direitos, e ao mesmo tempo confere aspirações" (BOURDIEU, 1983, p. 4). Para o autor, a educação teria perdido o seu papel de instância transformadora, passando a funcionar como agente de reprodução e legitimação das desigualdades sociais. Desse modo, o sistema de ensino seria induzido a cumprir duas funções básicas: a de fazer com que as classes mais baixas (leia-se negras) reconheçam a 
cultura das classes mais altas (leia-se brancas) como a única e legítima, além de impedir que as classes tidas como inferiores tenham acesso às expressões culturais que as constituem.

Partindo daí, podemos pensar nas aspirações manipuladas pela escola, tais como a inculcação de um pensamento e cultura específicos, a construção de uma noção de cidadania e de modelo de cidadão, as aspirações profissionais etc. Nesse sentido, entendemos que os valores apresentados pela escola como legítimos para uma construção social libertadora nada mais são do que mecanismos de manutenção de um sistema de desigualdades, deslegitimações, preconceitos e estereotipações que se apresentam como supostos caminhos transformadores, tanto para os alunos e alunas quanto para a comunidade escolar e, de forma mais ampla, para a sociedade em geral.

A escola atua de forma direta nas aspirações subjetivas, identitárias e profissionais dos estudantes e apresenta uma identidade alheia a ele/a, ou seja, a de um sujeito tido como universal (branco, homem, heterossexual, magro, classe alta, sem necessidades especiais, por exemplo). Essa atuação se dá tanto por meio das ideias de colonização e embranquecimento quanto por meio da tentativa de imposição de uma identidade única, a partir de um ideal de homogeneização, da busca por um aluno padrão, ou essencial. Assim, ela influencia de forma a anular a possibilidade do desenvolvimento de suas aspirações e identidades individuais e da busca de um autorreconhecimento por parte do/a educando/a.

Nessa perspectiva, entendemos a colonização como o processo de violência física e simbólica, ao qual sociedades não europeias foram (e são) submetidas, a fim de imposição de poder. Assim, o modo de enxergar o mundo, a cultura, os saberes europeus são vistos como os únicos modelos válidos de pensamento, estética, representações, subjetividades e de humanidade, relegando aos tidos como outros a posição de subalternos.

A partir dessa discussão, podemos pensar o ideal de embranquecimento como um processo histórico que atravessa a sociedade brasileira, uma vez que não é de hoje que se busca este status de ser europeu, ou seja, branco. Assim, embranquecer é buscar não apenas a aproximação de características físicas do homem branco e da mulher branca, mas também da sua maneira de conceber e se relacionar consigo mesmo/a e com o mundo. No contexto escolar, podemos notar essa concepção a partir da própria construção curricular, bem como dos materiais didáticos, nas práticas escolares, as quais privilegiam um saber e uma cultura específicos quase sempre pautados por uma perspectiva eurocêntrica.

Nesse mesmo contexto, é importante destacar as dificuldades de implementação da lei 10639/o3, cujas contribuições estão postas como desafio para a comunidade escolar repensar suas práticas no sentido de tornar a escola um espaço realmente inclusivo, plural, múltiplo, onde a juventude negra se reconheça especialmente através de conteúdos curriculares também afrocentrados.

Argum., Vitória, v. 12, n. 1, p. 50-66, jan./abr. 2020. | ISSN 2176-9575 
Entretanto, podemos entender que a escola funciona como um mecanismo colonial que trabalha no sentido de homogeneizar crianças e jovens, partindo de uma cultura e saberes específicos. Além disso, àqueles e àquelas que não se enquadram nesse padrão, resta a desvalorização, a deslegitimação de suas existências, complexidades, diferenças, subjetividades e, por conseguinte, de suas bagagens culturais. Podemos, baseando-nos em Fanon (2008), discutir que "[...] a civilização branca, a cultura europeia, impuseram ao negro um desvio existencial. [...] aquilo que se chama de alma negra é frequentemente uma construção do branco" (FANON, 2008, p. 30).

Dessa forma, pensamos que, no caso do aluno negro, ele é deslegitimado duas vezes: a primeira por não estar no padrão branco e por ele representar uma coletividade. Ele nunca é visto como um indivíduo, mas representante de um grupo homogêneo, que possui os mesmos gostos, que detém os mesmos saberes e, muitas vezes, a escola, embora pareça estar contribuindo para um trabalho que pense a diversidade $\mathrm{e}$ complexidade humana, atua numa segunda-via de construção racista: a falsa legitimação do/a aluno/a negro/a.

No caso das jovens negras, soma-se a isso a questão do gênero, uma vez que, estando fora desse padrão branco, está em desacordo com o padrão masculino. Assim, é importante atentar para as discussões acerca da interseccionalidade, travadas, dentre outras autoras, por Kimberly Crenshaw (2002). Ela propõe a análise dos conflitos sociais a partir da observação de uma rede de opressões que são impostas à vida de mulheres negras. Nesse sentido, visa discutir como essas relações se alteram e tencionam quando inserimos um olhar que observa conjuntamente gênero e raça.

\section{Identidades e culturas juvenis negras}

Ao discorrer a respeito de práticas juvenis em um contexto de jovens pobres, Dayrell pontua que:

Ao mesmo tempo, é preciso enfatizar que as práticas culturais juvenis não são homogêneas e se orientam conforme os objetivos que as coletividades juvenis são capazes de processar, num contexto de múltiplas influências externas e interesses produzidos no interior de cada agrupamento específico (DAYRELL, 2007, p. 1110).

Partindo disso, entendemos que a sociedade, de modo geral, já compreende o/a jovem em diversos contextos de maneira homogeneizante. Contudo, é importante perceber que o/a jovem ao qual essas características são atribuídas está dentro de um padrão previamente estabelecido, conforme dissemos anteriormente.

Ao jovem negro e à jovem negra não é nem estabelecida, de uma forma mais ampla, a ideia de que desenvolve práticas culturais. Se pensarmos nas manifestações mais discriminadas ou criminalizadas, elas estarão em alguma medida relacionadas a uma origem racial. É o caso do Funk, do Hip Hop e do grafite, por exemplo.

Em relação ao Funk, Claudia Ribeiro aponta que:

Argum., Vitória, v. 12, n. 1, p. 50-66, jan./abr. 2020. | ISSN 2176-9575 
Esse fenômeno cultural que atravessou quase quatro décadas como preferência de audiência dessa juventude, no entanto, ainda sofre com recorrentes estratégias de desqualificação e de cerceamento, não sendo reconhecido como importante partícipe da identidade cultural dos jovens das camadas populares em todos os âmbitos, inclusive o escolar (RIBEIRO, 2017, p. 10).

Essa discriminação se dá na sociedade de modo geral, obedecendo aos padrões de cooptação e embranquecimento gerados pelo sistema capitalista/ racista em que estamos inseridos. Assim, o passinho ${ }^{8}$, por exemplo, passa a ser aceito como manifestação cultural quando consegue adesão nas classes mais altas e por uma elite branca, que recria como novo padrão estético. O mesmo aconteceu com o Funk e o Charme quando foram incorporados por jovens de classe média nas novelas da televisão.

Nos afastando de uma discussão que apenas exclui o/a jovem negro/a de qualquer protagonismo, pretendemos observar como, a partir de diversos esforços do Movimento Negro, como a promulgação da Lei 10.639/03 (BRASIL, 2003), possibilitaram que se pudesse inserir o/a negro/a minimamente em um patamar de discussão no interior do ambiente escolar.

Entendemos, aqui, a escola como o espaço de excelência na prática de uma educação formal, uma vez que é ela quem atribui os diplomas, créditos e se incumbe de passar os conteúdos curriculares exigidos nos exames e documentos legais do país. Ela foi, ainda, responsável por formular categorias de identificação etária, tais como as próprias noções de infância e adolescência.

No entanto, podemos perceber que esta formalidade foi sendo, de alguma forma, substituída pelas próprias vivências dos alunos e alunas, reconfigurando a maneira como elas se estruturam e a forma como eles e elas constroem suas sociabilidades.

De acordo com Barbosa, podemos pensar que:

Se foi a escola a principal responsável pelo surgimento das categorias de infância e juventude como se configuram atualmente, pode-se dizer que também ocorre hoje o processo inverso, e, assim, os jovens e as crianças, que foram isolados desde o início dos tempos modernos para passarem por um período de formação moral e intelectual separado da sociedade dos adultos, estariam recriando tal espaço com suas novas demandas. Isto porque, o isolamento de crianças e jovens permitiu a estes um contato maior entre si e o estabelecimento de redes de sociabilidade juvenis e infantis específicas que passaram a ter a escola como referência. Abre-se, assim, a possibilidade de inverter, inclusive, a função de adestramento e de disciplina autoritária inicial da escola (BARBOSA, 2007, p. 2).

\footnotetext{
${ }^{8}$ Passinho é uma modalidade de dança muito popular entre jovens negros, principalmente de favelas cariocas. Surgido no funk, une elementos de movimentos corporais de diversos outros tipos de dança. No Rio de Janeiro, foi institucionalizado patrimônio cultural do Rio de Janeiro, a partir da aprovação do Projeto de Lei $\mathrm{n}^{0} 6381$ de 29 de junho de 2018 (RIO DE JANEIRO, 2018), da vereadora Verônica Costa. Ele é responsável pela criação de festivais e seus dançarinos participam de diversas apresentações ao redor do mundo.
} 
A partir do autor, podemos considerar que se a escola elabora e constrói a categoria juventude, esse mesmo local não se apresenta como constitutivo da juventude negra, o que vem ao encontro da nossa indagação que aponta para o fato de que tal categoria é construída a partir de discursos e práticas homogeneizantes. Nesse sentido, vale destacar o que nos parece uma contradição, uma vez que a escola pública, por exemplo, é ocupada em sua maioria por jovens negros/as. Para nós, importa o espaço escolar como aquele em que este/esta jovem, ao ter um modelo social pré-estabelecido, reformula este modelo, por meio de suas estratégias de sociabilidade com os demais inseridos na instituição.

Se, para alguns/algumas jovens, a escola parece um não-lugar, um espaço nem sempre acolhedor e atrativo, para muitos deles e delas se configura como um dos poucos lugares, senão o único, onde é possível a realização de trocas socializadoras. Essa interação faz com que a própria maneira de ser jovem seja constantemente reelaborada e alterada, a partir de tendências econômicas, sociais e midiáticas, por exemplo.

Assim, a categoria jovem não é apenas aquela pautada pela escola, que aprisiona em um modelo, mas é frequentemente e sempre de acordo com o contexto de interação em que ele/ela está inserido/a, reescrita, e por ele/a mesmo/a. É nesse espaço que as identidades se expressam e se reconfiguram, tendo as culturas juvenis como possibilidade de produção de mecanismos para o desenvolvimento desse processo de reconfiguração identitária.

A discussão sobre identidade permeia diversos debates entre as ciências humanas e, longe de estabelecer uma categoria com conceito fechado, nesse caso a juventude negra, se reinventa e amplia dia após dia. Entendendo a identidade como aquilo que classifica o indivíduo, a partir de uma perspectiva de classe, raça, faixa etária, cultura, ela se constitui como um dos pontos principais que diferencia os seres humanos entre si e entre grupos.

\section{Para Munanga:}

A identidade é uma realidade sempre presente em todas as sociedades humanas. Qualquer grupo humano, através do seu sistema axiológico sempre selecionou alguns aspectos pertinentes de sua cultura para definir-se em contraposição ao alheio. A definição de si (autodefinição) e a definição dos outros (identidade atribuída) têm funções conhecidas: a defesa da unidade do grupo, a proteção do território contra inimigos externos, as manipulações ideológicas por interesses econômicos, políticos, psicológicos etc. (MUNANGA, 1994, p. 177-78).

A partir da afirmação de Munanga, podemos conceber a ideia de que a identidade se caracteriza como um meio pelo qual os indivíduos passam, ao mesmo tempo, a se reconhecer em relação ao/a outro/a, individualmente, e diferenciam-se com relação a outros grupos e culturas. Essa identização (MELUCCI, 2004) se dá por meio da observação das diferenças que uns apresentam com relação aos/às outros/as. Assim, pensar a identidade é sempre pensar em processo de diferenciação ou contraposição. É possível se reconhecer como um indivíduo a partir da existência do/a outro/a, o/a diferente. 
Além disso, é importante pensarmos a identidade como uma categoria relacional, uma vez que essa diferenciação entre o eu e o/a outro/a se dá de forma simultânea, por meio de uma interação. A partir disso, podemos perceber que a identidade se formula a partir de um processo em que, ao mesmo tempo em que eu me diferencio do/a outro/a, atribuindo características a ele/ela, o/a outro/a formula aquilo que ele pensa que eu seja. Assim,

[...] a questão da identidade nunca é colocada no entendimento apenas do que eu sou, mas do que os outros imaginam que eu seja, isto é, mostra-se como algo relacional, que depende, portanto, de interação. Isto quer dizer que o indivíduo não recebe sua identidade passivamente, mas se apropria, interpreta-a e a negocia, pois a identidade social é intrinsecamente ligada a uma sucessão de deslocamentos num espaço de posições sociais (PINHEIRO LIMA, 2014, p. 198).

Partindo desse pressuposto, é possível entender que a identidade se configura como um processo interacional, tecido por meio dos processos de socialização (DUBAR, 2005), em que o indivíduo (re)negocia sua identidade o tempo todo, a partir da interação com o ambiente e com os demais indivíduos inseridos nele.

Desse modo, pensar o/a jovem negro/a, a partir de uma postura educacional que insira a cultura negra nos espaços escolares deve se aproximar de uma pedagogia que propicie o contato com a possibilidade de saber que existem outras formas de organização do pensamento, do discurso, da vida em sociedade. Acreditamos que seja primordial atentar para que esta cultura(s) afro-brasileira(s) levada(s) para dentro da escola não $\operatorname{deva}(\mathrm{m})$ visar uma definição uniformizada do que seria(m), mas, assim como apresentado por Stuart Hall, esta representação precisa ter foco:

Em sua expressividade, sua musicalidade, sua oralidade e na sua atenção rica, profunda e variada à fala; em suas inflexões para o vernacular e o local; em sua rica produção de contranarrativas; e, sobretudo, em seu uso metafórico do vocabulário musical, a cultura negra popular tem permitido trazer à tona, dentro de modos mistos e contraditórios, até da cultura popular mais comercial, os elementos de um discurso que é diferente - outras formas de vida, outras tradições de representação (HALL, 2003, p. 154).

Tendo as culturas juvenis negras como espaço de representação e de identidade, é através delas que esse/essa jovem negro/a que, assim como abordado por Barbosa (2007), se reformula por meio de suas interações no ambiente escolar. Se estabelecem constantemente novas maneiras de ser jovem negro/a na sociedade brasileira, para além dos estereótipos negativos reforçados muitas vezes pela própria escola, mas também se reelabora com o intuito de não se mostrar apenas como uma ideia de negro ou negra que o sistema educacional atual vem tendendo a formular, ou seja, uma construção branca sobre o que é ser negro/a.

Considerando as suas aspirações individuais e coletivas, suas características - inclusive físicas - que os/as diferenciam, uma vez que ser negro/a não demarca uma tonalidade de pele, textura de cabelo, formato de nariz específico, mas um conjunto de traços, físicos e psicológicos, simbólicos e subjetivos, a escola precisa se abrir a um debate mais amplo no que tange à questão racial, uma vez que o/a negro/a não deve ser apenas pensado/a a partir da ótica que o/a entende sempre como um sujeito que está fadado/a 
à sua condição racial e que, por isso, não pode aspirar outras coisas que, socialmente, não se atribuem a ele/ela.

Dizemos isso porque a escola, em determinado momento, não retratava o/a negro/a ou, quando o fazia, era de maneira a minimizá-lo/a com relação ao/à branco/a. É primordial que, ao adotar ações de valorização - tais como práticas educacionais que considerem a sua aceitação estética, bem como a inclusão de saberes oriundos da cultura negra e africana nos materiais, currículos e atividades, em geral - não se crie uma ideia de hierarquização desse grupo, onde se pode classificar quem é ou não negro/a de verdade, quais os tipos de músicas, vestimentas, cabelos e comportamentos um/a negro/a deve adotar. Isto não contribui para o fortalecimento desse/a jovem, tão pouco o/a conduz para um processo de formulação da sua própria identidade, mas apenas o/a joga em outro ideal que muitos/as não poderão e/ou nem desejarão alcançar.

Nilma Lino Gomes pontua que jovens negros/as acabam por construir identidades positivas fora dos espaços formais de socialização, como a escola, por exemplo. Ao analisar jovens de diferentes grupos ligados à cultura afro-brasileira, de vertentes distintas, destaca-se a ideia positiva do ser negro/a, em contraposição aos discursos comparados às vivências desses/as jovens na escola. Para a autora:

[...] cada vez mais, a escola precisa dialogar com os outros espaços educativos em que os jovens produzem cultura e se constroem enquanto sujeitos sociais. Além disso, a escola precisa considerar fatores como a raça/etnia e o gênero no processo de construção da identidade juvenil, valorizando-os e possibilitando aos jovens um conhecimento mais elaborado sobre essas relações e o seu desenvolvimento no decorrer da história, da política e da cultura (GOMES, 2004, p. 15).

Dessa forma, mais do que implementar a Lei 10.639/o3 ou a realização simples de ações pontuais que insiram uma ideia geral do que é o/a negro/a, apresentando com uma única possibilidade de ser, a escola precisa enfrentar o desafio de incorporar, através de métodos e conteúdos, os saberes, manifestações culturais, anseios e experiências que esses/as jovens possuem, elaboram e executam fora do espaço institucional.

\section{Considerações finais}

Uma das principais provocações deste texto diz respeito à importância de a escola pensar o/a jovem negro/a que se constitui identitariamente, muitas vezes, em contraposição/diferenciação à lógica homogeneizante presente no seu espaço e que caracteriza a juventude na sua totalidade. Assim, o/a jovem negro/a, no seu processo de diferenciação, por vezes, é adjetivado em decorrência de sua conduta desviante, na medida em que a escola não contempla as manifestações culturais negras. O diferente existe, mas está invisibilizado.

A partir do exposto, podemos pensar que a realização de práticas educacionais que visem uma discussão sobre estética, cultura e identidade com esses/as jovens pode funcionar de forma bastante efetiva no processo de implantação de práticas antirracistas no ambiente escolar. No entanto, é de suma importância que estas práticas sigam na 
contramão de uma postura bastante adotada pela escola: a homogeneização do corpo discente e, neste caso, do corpo discente negro e jovem.

Muito embora a escola compreenda em suas instalações jovens negros e negras com diferentes vivências e influências, que partem de diferentes formas de construção de pensamento, se aproximam de diversas manifestações culturais e aspirem a objetivos completamente diversos, ainda há uma grande resistência em incorporar essas tendências novas trazidas por eles para dentro do espaço escolar. A sua reação é, ainda de forma muito forte, de rechaçamento de qualquer possibilidade de considerá-los/las igualmente produtores/as de saber e essa uniformização vem ocorrendo por diferentes vieses.

Se, antes, isso se manifestava por meio de uma postura de total apagamento e/ou subvalorização desse grupo racial, nos dias de hoje, acontece através da tentativa de homogeneizá-los/las seguindo uma nova lógica, que é a de inclui-los/las em um padrão do ser negro/a que os/as aprisiona e desconsidera suas individualidades, numa verdadeira demonstração de desconhecimento do que é ser jovem negro/a no Brasil.

Desse modo, incorporar debates, oficinas e discussões que visem o aumento da autoestima dos/as jovens negros/as, assim como a possibilidade de auxiliar no processo de auto aceitação, bem como na construção de uma visão positivada sobre si mesmos/as em uma sociedade que coloca o/a negro/a em posição de inferioridade é, sem dúvida, um passo no sentido da promoção da equidade e do desenvolvimento da cidadania desses/as alunos/as. Entretanto, essas práticas devem visar a emancipação desses/as jovens, não a troca de uma prisão de identidade por outra, igualmente generalizante.

Pretendemos, com isso, trazer para o debate o fato de que inserir o/a negro/a no sistema educacional e nas práticas escolares é mais do que fazer turbantes, tranças, dançar/ jogar capoeira, fazer pinturas corporais ou falar de religiões de matrizes africanas. Temos jovens negros e negras que não se associarão a nenhuma dessas vivências; alguns deles e delas desejarão continuar com processos químicos nos cabelos, não professarão crenças em orixás, inkises ou voduns, por exemplo; alguns e algumas não se aproximarão do funk, do hip hop ou do samba.

Pensar os/as jovens negros/as dentro do espaço escolar é pensar em suas complexidades como indivíduos. É considerar que há espaço para as suas subjetividades, desejos e anseios que nem sempre poderão ser mapeados. É claro que precisamos abrir o espaço de discussão a respeito da história e cultura dos negros e dos africanos - das negras e das africanas, muito mais invisibilizadas por conta do gênero - como garantido pela lei 10.639/o3. No entanto, este mecanismo não pode funcionar para atingir o efeito inverso: a criação de outros estereótipos ou construções arquetípicas a respeito do ser negro/a, as quais podem, da mesma maneira, aprisionar as individualidades.

Torna-se importante pensar, então, como pontua Hall (2003), na necessidade do fim da noção de um sujeito negro essencial, a fim de fornecer ao/à jovem a possibilidade de escolha e formulação de sua própria individualidade por meio do processo educacional

Argum., Vitória, v. 12, n. 1, p. 50-66, jan./abr. 2020. | ISSN 2176-9575 
que vise a sua emancipação real. Dessa forma, se poderá articular identidade, negritude, juventude e educação.

\section{Referências}

ABRAMO, Helena. Considerações sobre a tematização social da juventude no Brasil. Revista Brasileira de Educação, Rio de Janeiro: ANPED, n. 5, p.25-36, 1997.

ALMEIDA, S. L. de. O que é Racismo Estrutural? Belo Horizonte (MG): Letramento, 2018.

BARBOSA, Alexandre P. Muitas palavras: a discussão recente sobre juventude nas Ciências Sociais. Ponto Urbe [Online], n. 1, 2007. Disponível em:

https://journals.openedition.org/pontourbe/1203. Acesso em: 10 mar. 2019.

BOURDIEU, Pierre. A juventude é apenas uma palavra. Rio de Janeiro: Marco Zero, 1983. Disponível em: http://www.observatoriodoensinomedio.ufpr.br/wpcontent/uploads/2014/o4/a-juventude-e-apenas-uma-palavra-bourdieu.pdf. Acesso em: 13 abr. 2019.

BRASIL. Câmara Federal. Proposta de Emenda à Constituição nº 115, de 2015. Proponente: Benedito Domingos. Brasília (DF), 2015. Disponível em: https://www25.senado.leg.br/web/atividade/materias/-/materia/122817/pdf. Acesso em: 3 abr. 2020.

BRASIL. Ministério da Educação. Plano nacional de implementação das diretrizes curriculares nacionais para a educação das relações étnicorraciais e para o ensino de hitória e cultura afro-brasileira e africana. Brasília (DF): Petry, 2009.

BRASIL. Lei 11.645, de 10 de março de 20o8. Altera a Lei no 9.394, de 20 de dezembro de 1996, modificada pela Lei no 10.639, de 9 de janeiro de 2003, que estabelece as diretrizes e bases da educação nacional, para incluir no currículo oficial da rede de ensino a obrigatoriedade da temática "História e Cultura Afro-Brasileira e Indígena". Brasília (DF), 2008. Disponível em:

http://portal.mec.gov.br/index.php?option=com_docman\&view=download\&alias=10101 -lei-11645-10-03-2008\&Itemid=30192. Acesso em: 3 abr. 2020.

BRASIL. Lei 10.639, de o9 de janeiro de 2003. Altera a Lei. 9.394, de 20 de dezembro de 1996, que estabelece as diretrizes e bases da Educação nacional, para incluir no currículo oficial da Rede de Ensino a obrigatoriedade da temática "História e cultura Afro-Brasileira” e dá outras providências. Brasília (DF), 2003. Disponível em:

http://etnicoracial.mec.gov.br/images/pdf/lei_10639_09012003.pdf._Acesso em: 15 mar. 2019.

CRENSHAW, Kimberlé. Documento para o encontro de especialistas em aspectos da discriminação racial relativos ao gênero. Estudos Feministas, Florianópolis, v. 10, n. 1, p. 171-188, jan. 2002. 
CONSELHO REGIONAL DE SERVIÇO SOCIAL (Minas Gerais). Especial Consciência Negra: A carne mais exótica do mercado. Belo Horizonte, [201-]. Disponível em: https://www.cress-mg.org.br/Home/PDF/4185ef77-fe2e-451d-9ab4-03a76ddc8813. Acesso em: 5 abr. 2020.

COSTA, A. Onde começa a exclusão?: trajetória sócio-racial de jovens negros em cumprimento de medida socioeducativa no Distrito Federal. Dissertação apresentada ao Programa de Pós-Graduação em Relações Étnico-Raciais do CEFET-RJ, Rio de Janeiro, 2019.

DAYRELL, Juarez. A escola "faz" as juventudes? Reflexões em torno da socialização juvenil. Educ. Soc., Campinas, v. 28, n. 100 - Especial, p. 1105-1128, out. 2007.

DUBAR, Claude. A socialização: construção das identidades sociais e profissionais. Tradução: Andréa Stahel Monteiro da Silva. 1. ed. São Paulo: Martins Fontes, 2005.

FANON, Frantz. Pele negra, máscaras brancas. Tradução de Renato da Silveira. Salvador: EDUFBA, 2008.

FREIRE, Paulo. Pedagogia do oprimido. 17. ed. Rio de Janeiro: Paz e Terra, 1987.

FOTO de exército revistando mochila de crianças no Rio choca internautas. Notícias UOL online. Rio de Janeiro, 928 fev. 2018. Disponível em: https://www.bol.uol.com.br/noticias/2018/02/23/foto-de-exercito-revistando-mochilade-criancas-no-rio-choca-internautas.htm?cmpid=copiaecola. Acesso em: 12 set. 2019.

FÓRUM PERMANENTE DE EDUCAÇÃO E DIVERSIDADE ÉTNICO-RACIAL DE MINAS GERAIS. Nota sobre o novo acordo ortográfico, s.d. Disponível em: https://sites.google.com/site/forumeducacaoediversidademg/nota-sobre-o-novoacordo-ortografico Acesso em: 4 abr. 2020.

GOMES, Nilma L. Juventude, práticas culturais e negritude: o desafio de viver múltiplas identidades. In: Reunião anual da ANPED, 27., 2004, Caxambu. Anais [...]. Caxambu, 2004. Disponível em: http://www.anped.org.br/sites/default/files/t218.pdf. Acesso em: 2 mar. 2019.

HALL, S. Que "negro" é esse na cultura negra. In: HALL, S. Da Diáspora: identidades e mediações culturais. Belo Horizonte: UFMG; UNESCO, 2003. p. 335-349.

LOVISI, P. Jovem de clase média alta é preso por suspeita de tráfico em boates de $\mathrm{BH}$. Estado de Minas Gerais, Belo Horizonte, 18 fev. 2019. Disponível em: https://www.em.com.br/app/noticia/gerais/2019/o2/18/interna_gerais,1031647/jovemde-classe-media-alta-e-preso-suspeita-trafico-em-boates-bh.shtml. Acesso em: 30 set. 2019. 
MARGULLIS, Mario; URRESTI, Marcelo. La juventud es más que uma palabra. In: ARIOVICH, Laura [et al.]. La juventud es más que uma palabra. Buenos Aires: Biblos, 1996. p. 13-30.

MELUCCI, A. O jogo do eu: a mudança de si em uma sociedade global. São Leopolodo: UNISINOS, 2004.

MUNANGA, Kabengele. Identidade, cidadania e democracia: algumas reflexões sobre os discursos anti-racistas no Brasil. In: SPINK, Mary Jane Paris (Org.). A cidadania em construção: uma reflexão transdisciplinar. São Paulo: Cortez, 1994.

PAIS, José Machado. Culturas Juvenis. 2. ed. Lisboa: Imprensa nacional-Casa da Moeda, 2003.

PINHEIRO LIMA, J. C. Do desmonte da favela ao Parque proletário: política assistencial? Revista Diversitas, São Paulo, n. 2, p. 186-223, 5 mar./abr. 2014.

RIBEIRO, C. Som de preto e favelado: o funk e a constituição de identidades juvenis no contexto escolar. 2017. Dissertação apresentada ao Programa de Pós-Graduação em Relações Étnico-Raciais do CEFET-RJ, Rio de Janeiro, 2017.

RIO DE JANEIRO (Município). Lei no 6381, de 29 de junho de 2018. Declara a dança do Passinho patrimônio cultural imaterial do povo carioca. Rio de Janeiro, 2018. Disponível em: https://leismunicipais.com.br/a/rj/r/rio-de-janeiro/leiordinaria/2018/639/6381/lei-ordinaria-n-6381-2018-declara-a-danca-do-passinhopatrimonio-cultural-imaterial-do-povo-carioca. Acesso em: 13 mar. 2019.

SILVA, C.; CAPRIGLIONE, L. Ele é sementinha do mal. Diário do Centro do Mundo. São Paulo, 23 set. 2019. Disponível em:

https://www.diariodocentrodomundo.com.br/essencial/ele-e-um-sementinha-do-malpm-paulista-vai-ate-a-casa-da-mae-do-garoto-pedir-para-ela-encomendar-o-caixaodo-filho. Acesso em: 30 set. 2019.

Heloise da Costa SIILVA. Autora e revisora

Mestra em Relações Étnico-Raciais pelo CEFET-RJ, onde foi Bolsista CAPES. Graduada em Letras pela UFRJ. Pesquisadora das Relações Étnico-Raciais, Linguagem, Racismo e Educação.

Carlos Henrique dos Santos MARTINS. Coautor

Doutor em Educação. Professor e Pesquisador do Programa de Pós-Graduação em Relações ÉtnicoRaciais do CEFET-RJ. 